\title{
Glypican 3 Overexpression across a Broad Spectrum of Tumor Types Discovered with Functional Genomic mRNA Profiling of a Large Cancer Database
}

Kirsten L. Moek, ${ }^{*}$ Rudolf S.N. Fehrmann, ${ }^{*}$ Bert van der Vegt,${ }^{\dagger}$ Elisabeth G.E. de Vries, ${ }^{*}$ and Derk J.A. de Groot

From the Departments of Medical Oncology* and Pathology, ${ }^{\dagger}$ University Medical Center Groningen, University of Groningen, Groningen, the Netherlands

\author{
Accepted for publication \\ May 24, 2018. \\ Address correspondence to \\ Derk Jan A. de Groot, M.D., \\ Ph.D., Department of Medical \\ Oncology, University Medical \\ Center Groningen, PO Box \\ 30.001, 9700 RB Groningen, \\ the Netherlands. E-mail: d.j.a. \\ de.groot@umcg.nl.
}

\begin{abstract}
Glypican 3 (GPC3), a membrane-bound heparan sulfate proteoglycan, is overexpressed in approximately $70 \%$ to $80 \%$ of hepatocellular carcinomas, but is not expressed commonly in healthy tissues. This raised interest in GPC3 as a drug target and several GPC3-targeting drugs are in clinical development. We therefore predicted GPC3 protein overexpression across tumors and validated these predictions. Functional genomic mRNA profiling was applied to the expression profiles of 18,055 patient-derived tumor samples to predict GPC3 overexpression at the protein level in 60 tumor types and subtypes using healthy tissues as reference. For validation, predictions were compared with immunohistochemical (IHC) staining of a breast cancer tissue microarray and literature data reporting IHC GPC3 overexpression in various solid, hematologic, and pediatric tumors. The percentage of samples with predicted GPC3 overexpression was $77 \%$ for hepatocellular carcinomas ( $n=364), 45 \%$ for squamous cell lung cancers $(n=405)$, and $19 \%$ for head and neck squamous cell cancers $(n=344)$. Breast cancer tissue microarray analysis showed GPC3 expression ranged from $12 \%$ to $17 \%$ in subgroups based on estrogen receptor and human epidermal growth factor receptor 2 status. In 28 of 34 tumor types for which functional genomic mRNA data could be compared with IHC there was a relative difference of $\leq 10 \%$. This study provides a data-driven prioritization of tumor types and subtypes for future research with GPC3-targeting therapies. (Am J Pathol 2018, 188: 1973-1981; https://doi.org/10.1016/ j.ajpath.2018.05.014)
\end{abstract}

In personalized medicine, identification of targetable tumorspecific or tumor-associated characteristics to increase therapeutic possibilities in cancer patients is of great value. Although many treatment protocols have been enhanced with novel drugs including molecularly targeted agents that inhibit specific oncogenic driver pathways, not all patients benefit because driver targets are not available for all tumor types. Interestingly, antigen targets for novel therapeutic approaches such as bispecific antibodies, antibody-drug conjugates, antibodies, or antibody fragments fused with a toxin, radioimmunoconjugates, and chimeric antigen receptors, do not have to be drivers of tumor growth because their task is to serve as an anchor to bind the compounds. This clearly increases the total number of available antigen targets in cancer.
In this context, glypican 3 (GPC3), a membrane-bound heparan sulfate proteoglycan, is an interesting antigen target. During embryogenesis, GPC3 is expressed abundantly in multiple tissues. ${ }^{1}$ After birth, GPC3 expression rarely is observed in healthy tissues, although overexpression is seen in regenerating tissues. For example, GPC3 overexpression is present in up to $83 \%$ of chronic nontumor cirrhotic livers; however, expression in healthy liver tissue and benign liver lesions is rare. ${ }^{3-8}$ In addition, GPC3

\footnotetext{
Supported by The Netherlands Organisation for Scientific Research (NWO)-VENI grant 916-16025 (R.S.N.F.), Bas Mulder award RUG 20135960 (R.S.N.F.) from the Alpe d'HuZes/Dutch Cancer Society, a Mandema stipend (R.S.N.F.), and the advanced European Research Council grant OnQview (E.G.E.d.V.).

Disclosures: None declared.
} 


$\begin{array}{ll}\text { Breast cancer } & \text { ER-neg/HER2-pos } \\ & \text { ER-pos/HER2-neg } \\ & \text { ER-pos/HER2-pos } \\ & \text { TNBC } \\ \text { CNS tumors } & \text { Anaplastic astrocytoma } \\ & \text { Anaplastic oligoastrocytoma } \\ & \text { Anaplastic oligodendroglioma } \\ & \text { Astrocytoma } \\ & \text { Ependymoma } \\ & \text { Glioblastoma } \\ & \text { Medulloblastoma } \\ & \text { Meningioma } \\ & \text { Oligoastrocytoma } \\ & \text { Oligodendroglioma } \\ & \text { Pilocytic astrocytoma } \\ \text { Adrenal cancer } & \text { Adrenocortical } \\ \text { Thyroid cancer } & \text { Anaplastic } \\ & \text { Papillary } \\ \text { Gastro-intestinal } & \text { Colorectal cancer } \\ & \text { Esophageal adenocarcinoma } \\ \text { cancer } & \text { Esophageal squamous cell carcinoma } \\ & \text { Gastric cancer } \\ & \text { Hepatocellular carcinoma } \\ & \text { Pancreas cancer } \\ & \text { Periampullary cancer } \\ & \end{array}$

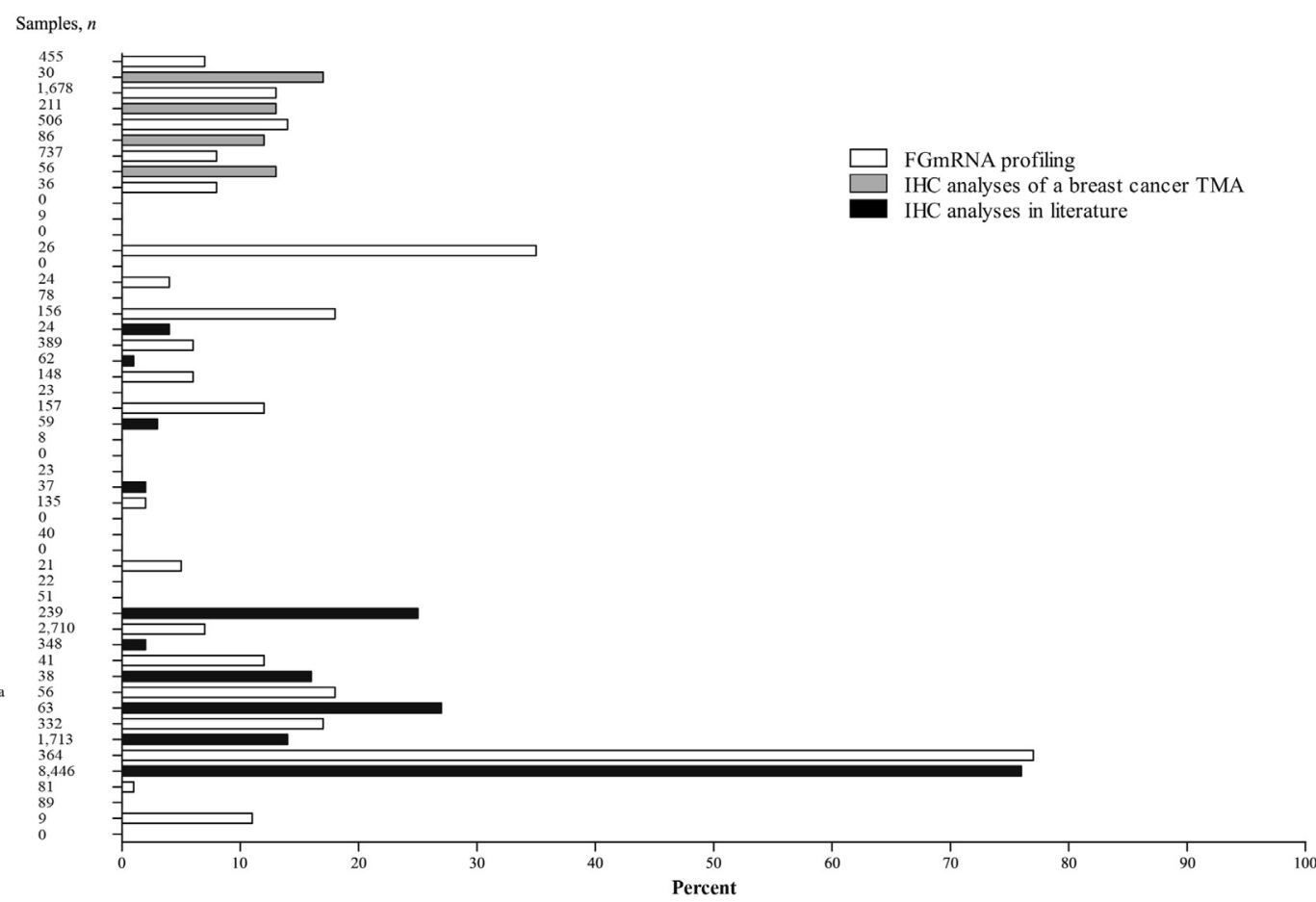

Figure 1 Glypican 3 (GPC3) overexpression rates in solid tumor types as determined with functional genomic mRNA (FGmRNA) profiling or immunohistochemical (IHC) analyses derived from our breast cancer tissue microarray (TMA) or literature data. The $x$ axis shows the percentage of samples with overexpression of GPC3. Tumor types including relevant subgroups are shown on the $y$ axis. CNS, central nervous system; ER, estrogen receptor; HER2, human epidermal growth factor receptor 2; TNBC, triple negative breast cancer.

overexpression is found in several tumors, most notably in approximately $70 \%$ to $80 \%$ of hepatocellular carcinomas (HCCs), but also in yolk sac tumors, gastric carcinoma, colorectal carcinoma, non-small cell lung cancer, and thyroid cancer. ${ }^{9-17}$

$\begin{array}{ll}\text { HNSCC } & \text { Nasopharyx } \\ \text { Gynecological } & \text { HNSCC } \\ \text { cancer } & \text { Cervical cancer } \\ & \text { Ovarian cancer } \\ \text { Vulva cancer } \\ \text { Lung cancer } & \text { Adenocarcinoma } \\ & \text { Neuro-endocrine } \\ \text { Melanoma } & \text { Squamous cell carcinoma } \\ & \text { Cutaneous } \\ & \text { Uveal } \\ & \text { Ewings sarcoma } \\ & \text { Leiomyosarcoma } \\ & \text { Liposarcoma } \\ & \text { Not otherwise specified } \\ & \text { Osteosarcoma } \\ & \text { Primitive neuroctodermal tumor } \\ & \text { Synovial sarcoma } \\ & \text { Undifferentiated sarcoma } \\ \text { Urogenital cancer } & \text { Bladder cancer } \\ & \text { Prostate cancer } \\ & \text { Chromophobe } \\ & \text { Clear cell } \\ & \text { Papillary } \\ & \end{array}$

Samples, $n$
GPC3 has specific characteristics that make it a potentially attractive drug target: protein expression is absent or at low levels in healthy adult tissues, it is located at the cell surface, and it is overexpressed by several tumor types. In

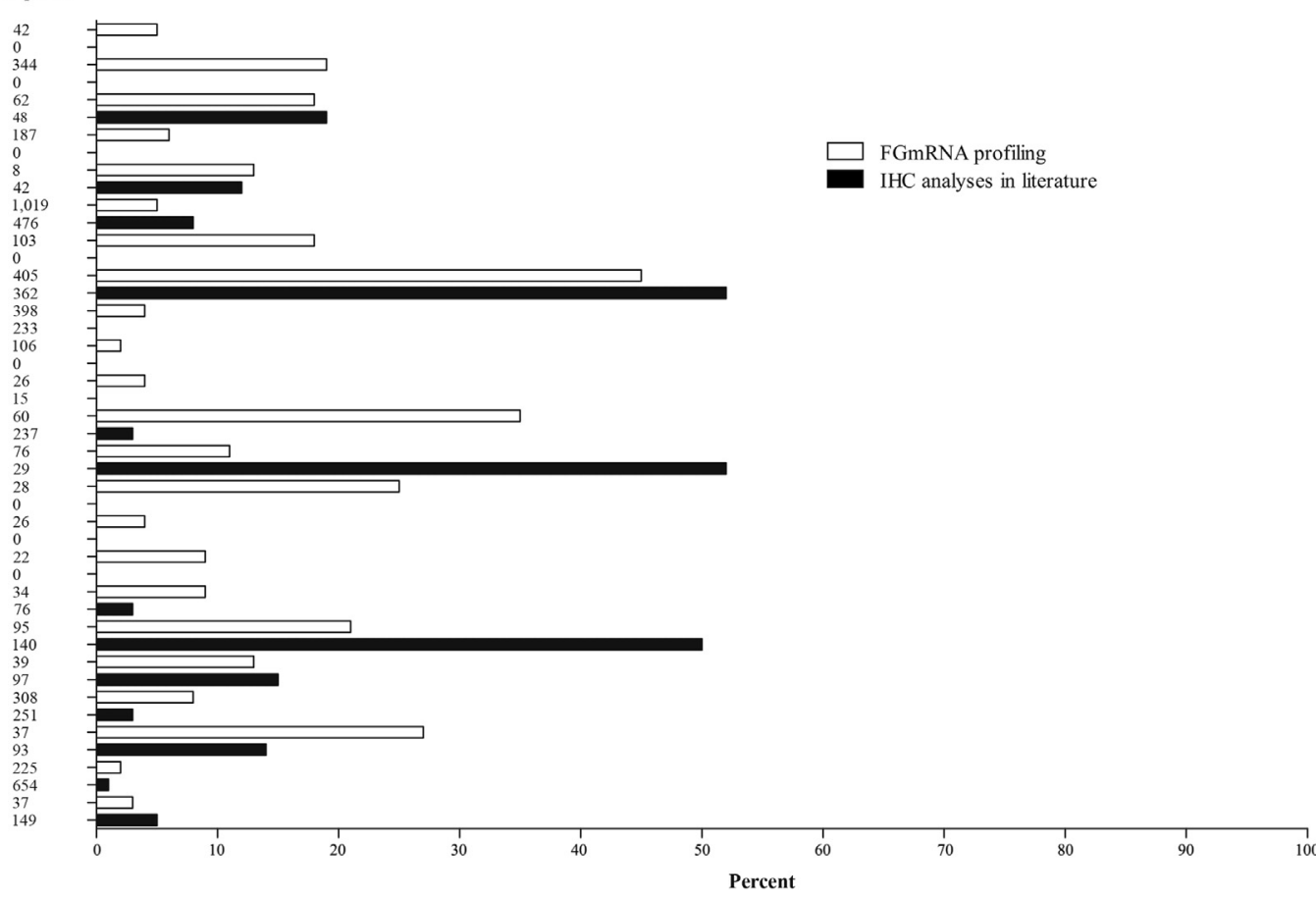

Figure 2 Glypican 3 (GPC3) overexpression rates in solid tumor types as determined with functional genomic mRNA (FGmRNA) profiling or immunohistochemical (IHC) analyses in literature. The $x$ axis shows the percentage of samples with overexpression of GPC3. Tumor types including relevant subgroups are shown on the $y$ axis. HNSCC, head and neck squamous cell cancer. 


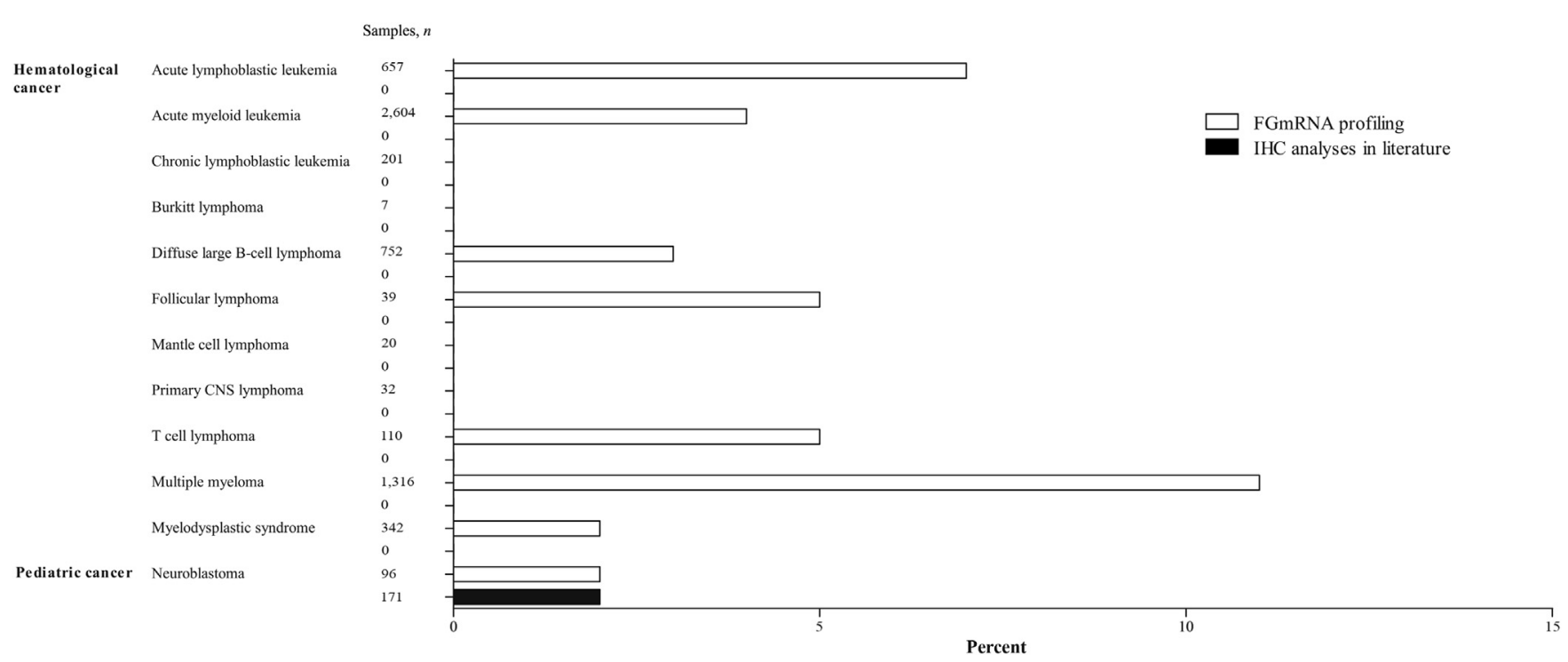

Figure 3 Glypican 3 (GPC3) overexpression rates in hematologic and pediatric tumors as determined with functional genomic mRNA (FGmRNA) profiling or immunohistochemical (IHC) analyses in literature. The $x$ axis presents the percentage of samples with overexpression of GPC3. Tumor types are shown on the $y$ axis. CNS, central nervous system.

this respect, it is critical to have good insight into its overexpression across several tumor types.

Immunohistochemical (IHC) analysis enables investigation of protein overexpression of GPC3 in various tumor types and subtypes. However, gaining insight into a broad range of tumors using IHC screening for the presence of this druggable target is time consuming and demands many resources. Functional genomic mRNA profiling (FGmRNA profiling) therefore was used to predict overexpression of GPC3 at the protein level. ${ }^{18}$ An advantage of this method is that it can correct a gene expression profile of an individual tumor for physiological and experimental factors that may not be relevant for the observed tumor phenotype.

In this study, FGmRNA profiling was applied to a large database containing a broad spectrum of tumor types and subtypes to predict GPC3 protein overexpression for each tumor type/subtype, using healthy tissue samples as reference. The predictions from FGmRNA profiling then were validated by comparing them with IHC staining of a breast cancer tissue microarray (TMA), derived from tumors of an independent set of patients. In addition, predicted GPC3 overexpression was compared with historical GPC3 protein overexpression IHC data derived from the literature.

\section{Materials and Methods}

\section{Acquisition of Expression Data}

Publicly available microarray expression data were extracted (Gene Expression Omnibus, https://www.ncbi.nlm.nih.gov/ geo). ${ }^{19}$ Gene Expression Omnibus accession numbers are provided in Supplemental Table S1. The analysis was restricted to the Affymetrix HG-U133 Plus 2.0 (GPL570) platform (Affymetrix, Santa Clara, CA). For each sample, metadata including patient information and experimental conditions were collected in the simple omnibus format in text file format. Relevant samples were selected using a twostep approach: automatic filtering on relevant keywords followed by manual curation. Samples were retained when raw data (CEL files) were available and when the samples were representative tumor tissue samples of patients or healthy tissue samples. Preprocessing and aggregation of raw data were performed according to the robust multiarray average algorithm with RMAExpress (version 1.1.0) using the latest CDF file from Affymetrix. ${ }^{20}$ Quality control of the resulting expression data were performed as previously described. ${ }^{18,21,22}$ A message-digest algorithm 5 hash for each

Table 1 Immunohistochemical Analysis of GPC3 Overexpression in a Breast Cancer Tissue Microarray Containing 391 Tumor Samples

\begin{tabular}{|c|c|c|c|}
\hline Tumor-receptor status & $\begin{array}{l}\text { GPC3-positive tumor samples, } \\
n / \text { total }(\%)\end{array}$ & $\begin{array}{l}\text { Tumor samples showing cytoplasmic } \\
\text { staining, } n^{*}\end{array}$ & $\begin{array}{l}\text { Tumor samples showing nuclear } \\
\text { staining, } n^{*}\end{array}$ \\
\hline ER positive & $28 / 211(13)$ & $7 \mathrm{IHC1}^{+}, 6 \mathrm{IHC}^{+}$ & $6 \mathrm{IHC}^{+}, 9 \mathrm{IHC}^{+}$ \\
\hline HER2 positive ${ }^{\dagger}$ & $5 / 30(17)$ & $2 \mathrm{IHC1}^{+}, 1 \mathrm{IHC}^{+}$ & $3 \mathrm{IHC}^{+}$ \\
\hline ER positive/HER2 positive & $10 / 86(12)$ & $2 \mathrm{IHC}^{+}, 2 \mathrm{IHC}^{+}, 1 \mathrm{IHC}^{+}$ & $5 \mathrm{IHC1}^{+}$ \\
\hline TNBC & $7 / 56(13)$ & $1 \mathrm{IHC}^{+}, 1 \mathrm{IHC}^{+}, 3 \mathrm{IHC}^{+}$ & $2 \mathrm{IHC1}^{+}$ \\
\hline
\end{tabular}

*Subdivided into staining intensity.

${ }^{\dagger}$ One core showed both cytoplasmic $\left(\mathrm{IHC}^{+}\right)$and nuclear $\left(\mathrm{IHC}^{+}\right)$staining and therefore is represented twice in the table.

ER, estrogen receptor; GPC3, glypican 3; HER2, human epidermal growth factor receptor 2; IHC, immunohistochemically; TNBC, triple negative breast cancer. 

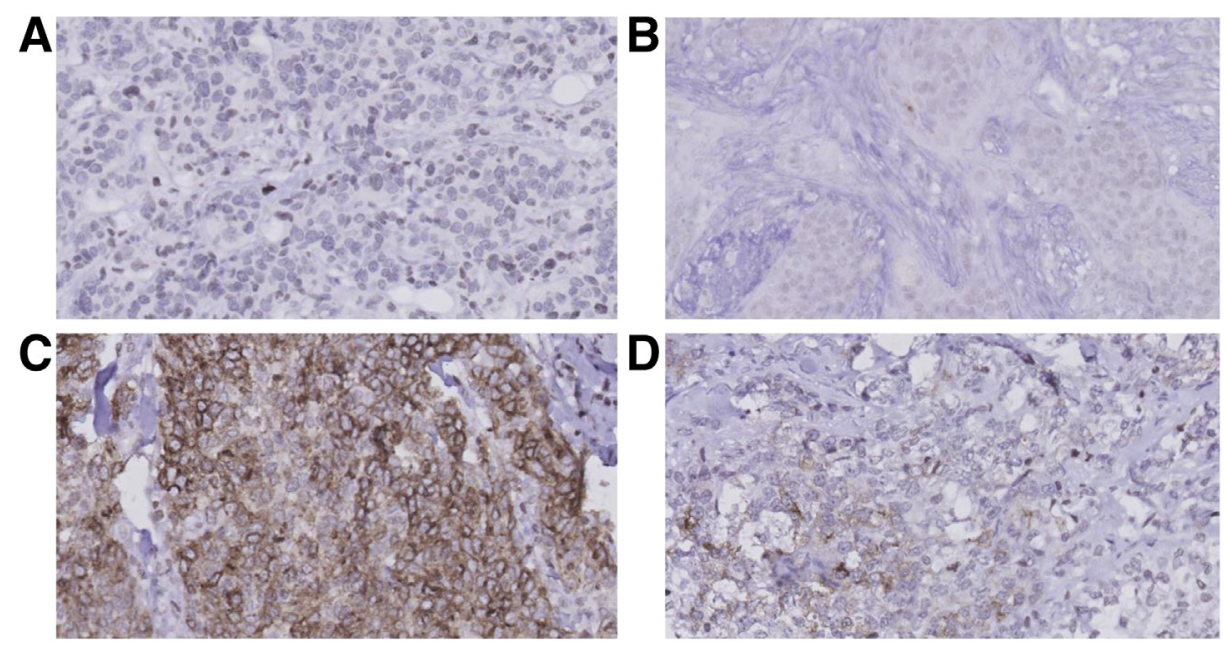

E
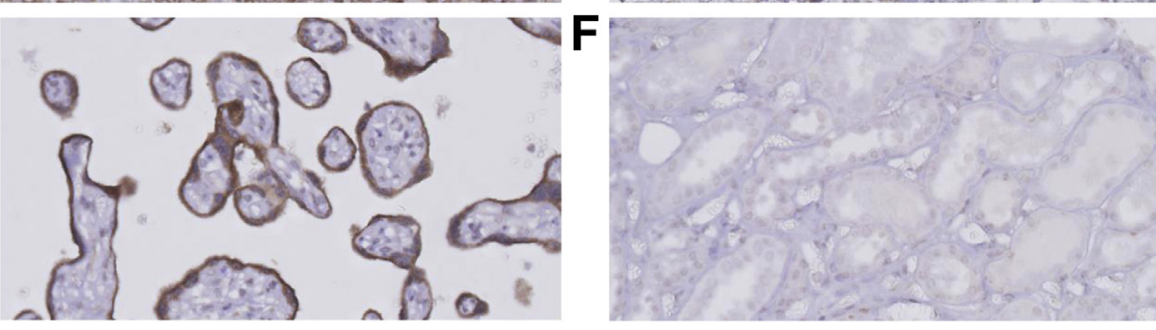

Figure 4 Representative examples of immunohistochemical glypican 3 (GPC3) staining results. Positive GPC3 staining is shown in brown. A: Strong nuclear staining of GPC3 in breast cancer. B: Weak nuclear staining of GPC3 in breast cancer. C: Strong GPC3 cytoplasm staining in breast cancer. D: Weak GPC3 cytoplasm staining in breast cancer. E: Strong GPC3 staining in placenta tissue (positive control). F: Negative staining of GPC3 in kidney tissue (negative control). Original magnification, $\times 40$. individual CEL file was used to identify and remove duplicate CEL files. For the breast cancer cohort, receptor status was collected or inferred as described previously. ${ }^{23-25}$

\section{Predicting Protein Overexpression of GPC3 with FGmRNA Profiling}

The FGmRNA profiling method is described in detail by Fehrmann et al. ${ }^{18}$ In short, 77,840 expression profiles of publicly available samples were analyzed with principal component analysis and it was found that a limited number of transcriptional components captured the major regulators of the mRNA transcriptome. Subsequently, a subset of transcriptional components that described nongenetic regulatory factors were identified. These nongenetic transcriptional components were used as covariates to correct microarray expression data and it was observed that the residual expression signal (ie, the FGmRNA profile) captured the downstream consequences of genomic alterations on gene expression levels.

The percentage of samples per tumor type, including relevant subgroups, then was predicted based on histotype (eg, adenocarcinoma) or receptor status (eg, breast cancer) with an increased FGmRNA signal for GPC3, which was used as a proxy for protein overexpression. The threshold was defined in the set of FGmRNA profiles of healthy tissues by calculating the 97.5th percentile for the FGmRNA signal of GPC3. For each tumor sample, GPC3 was marked as overexpressed when the FGmRNA signal was above the 97.5th percentile threshold as defined in the healthy tissue samples. Because the Affymetrix HG-U133 Plus 2.0 platform contains two probes representing GPC3, the highest percentage of samples with an increased FGmRNA signal was systematically reported.

\section{Immunohistochemical GPC3 Staining of Breast Cancer TMA}

Seven breast cancer TMAs containing residual tumor samples of patients treated for primary breast cancer in the University Medical Center Groningen between 1996 and 2005 were stained for GPC3. TMA construction and validation for breast cancer was described previously. ${ }^{26,27}$ In brief, TMAs were constructed as follows: the most representative tumor area was marked on a hematoxylin and eosin-stained section. By using the hematoxylin and eosin-stained section for orientation, three $0.6-\mathrm{mm}$ cores were taken from the selected area in the donor blocks and mounted on a recipient block, using a manual TMA device (Beecher Instruments, Silver Springs, MD). After this, 3- $\mu \mathrm{m}$ sections were cut from these TMA blocks using a standard microtome.

Tumor samples were stained using an anti-GPC3 antibody (clone 1G12, dilution 1:100; BioMosaics, Burlington, VT) on an automated Benchmark Ultra stainer (Ventana Medical Systems, Inc., Tucson, AZ). Normal placenta was used as a positive control and normal kidney tissue was used as a negative control.

Two authors (K.L.M. and D.J.A.d.G.) independently scored three cores of each tumor sample for staining intensity. Immunostains were excluded from IHC analysis if they were unrepresentative or unscorable owing to technical 
issues (eg, incomplete tissue transfer to the microscopic slide). The staining intensity was scored semiquantitatively as follows: 0 , negative; $1+$, weak; $2+$, moderate; and $3+$, strong; as described by Hirabayashi et al. ${ }^{6}$ A tumor sample was considered positive when weak, moderate, or strong GPC3 staining was seen in at least 5\% of tumor cells within at least one core. When staining was present in $>1$ core of one tumor sample the highest staining intensity consistently was reported. Different staining patterns (cytoplasmic or nuclear) were described. In case of a discrepancy between the two observers, a breast pathologist (B.v.d.V.) independently scored the tumor sample during a consensus meeting and a final verdict was reached.

\section{Literature Search}

To collect IHC data for GPC3 protein overexpression in cancer, PubMed was searched in April 2017 for relevant articles published in English. The following search terms were used in different combinations and spelling variants: "immunohistochemistry," "expression," "glypican 3," "GPC3," "cancer," "tumor." The retrieved articles were completely screened for the presence of IHC staining of patient tumor tissue. Case reports and reviews were excluded. Subsequently, the number of tumor samples analyzed and the percentages of tumor samples marked as GPC3 positive were recorded per tumor type and per article. GPC3 positivity was defined as being present when it was determined as positive in the original article. In addition, ClinicalTrials.gov was searched for ongoing studies with GPC3-directed therapies on June 26, 2017. The search terms "GPC3" or "glypican" were used.

\section{Results}

\section{Predicted Protein Overexpression of GPC3 by FGmRNA Profiling}

A total of 18,055 samples representing 60 tumor types, including relevant subgroups, and 3520 samples representing 22 healthy tissue types were identified. The median number of tumor samples analyzed per tumor type or subtype was 88 (interquartile range, 33 to 343 ), ranging from 7 in Burkitt lymphoma to 2710 in colorectal cancer.

A predicted GPC 3 overexpression rate in $77 \%$ of samples was observed for HCC, $45 \%$ for squamous cell lung cancer, $19 \%$ for head and neck squamous cell cancer, and $18 \%$ for squamous cell esophageal cancer. In lung cancer and esophageal cancer, the squamous cell histologic subtype showed higher predicted GPC3 overexpression compared with adenocarcinomas.

In breast cancer, the predicted GPC3 overexpression was receptor status-dependent, with $13 \%$ for estrogen receptor positive, $7 \%$ for human epidermal growth factor receptor 2 positive, $14 \%$ for estrogen receptor positive/human epidermal growth factor receptor 2 positive, and $8 \%$ for triple-negative breast cancers. In total, 22 of 60 tumor types and subtypes studied showed predicted overexpression in $\geq 10 \%$ of samples (Figures 1, 2, and 3). Predicted GPC 3 overexpression in at least $1 \%$ of samples was found in 51 of 60 tumor types and subtypes, including $8 \%$ for prostate cancer and $7 \%$ for colorectal cancer. Predicted GPC3 protein overexpression for all tested solid, hematologic, and pediatric tumors is shown in Figures 1, 2, and 3, additional information is provided in Supplemental Table S2.

\section{IHC Determined Protein Overexpression of GPC3 in a Breast Cancer TMA}

A total of 391 tumor samples, with an average of 2.74 assessable cores per tumor, were studied. GPC3 overexpression ranged from $12 \%$ to $17 \%$ in subgroups based on estrogen receptor and human epidermal growth factor receptor 2 status (Table 1). Both GPC3 cytoplasm and nuclear staining patterns of tumor cells were present in various intensities. Figure 4 shows representative staining patterns of GPC3 in breast cancer. Thirty tumor samples were unrepresentative or unscorable and therefore were excluded from analyses.

\section{Literature-Based GPC3 Protein Expression}

In total, 166 studies were identified that used IHC to determine GPC3 protein overexpression in 107 different tumor types and subtypes in 20,653 tumor samples. The number of samples analyzed per tumor type and subtype varied between 1 for Hürthle cell thyroid cancer to 8446 for HCCs, with a median of 49 (interquartile range, 18 to 147). In total, 19 different antibodies were used, of which the 1G12 monoclonal antibody from BioMosaics (1G12; Cell Marque, Rocklin, CA; and 1G12; Santa Cruz Biotechnology, Dallas, TX) was applied most frequently. Seventy different GPC3-positivity scoring systems were used.

In Table 2, GPC3 protein overexpression rates are shown for tumor types and subtypes for which data from two or more articles were available. Data concerning GPC3 overexpression in additional tumor types and subtypes are shown in Supplemental Table S3.

\section{GPC3 Overexpression Rates Predicted by FGmRNA Profiling Compared with IHC Data for a Breast Cancer TMA or Historical IHC Data in Various Tumor Types as Reported in Included Articles}

For 34 tumor types and subtypes, both FGmRNA profiling and IHC protein data were available (Figures 1, 2, and 3). For 19 of these tumor types and subtypes, the GPC 3 protein expression predicted by FGmRNA profiling was higher than 
Table 2 Published Results Regarding Immunohistochemically Measured GPC3 Overexpression in Tumors

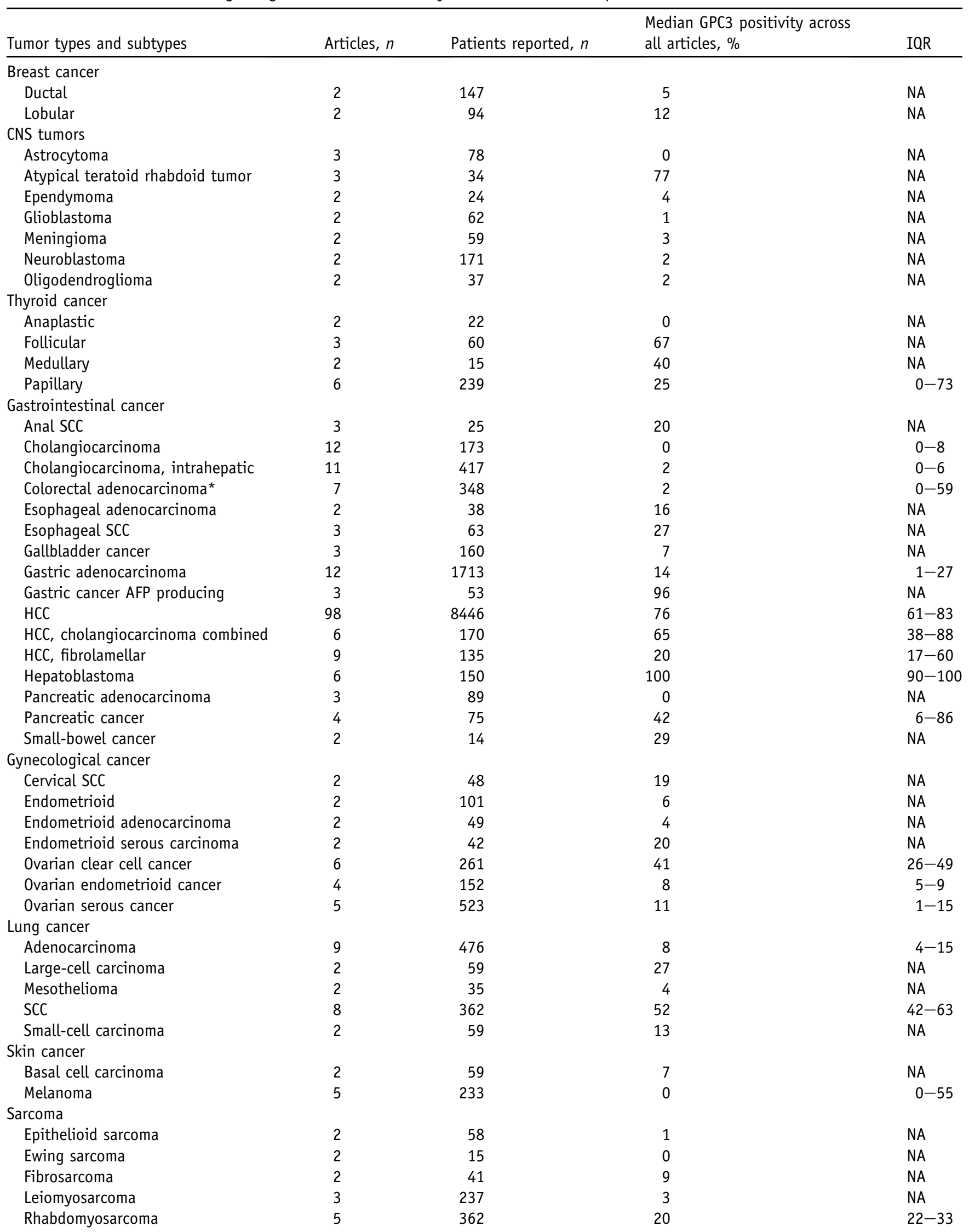


Table 2 (continued)

\begin{tabular}{|c|c|c|c|c|}
\hline Tumor types and subtypes & Articles, $n$ & Patients reported, $n$ & $\begin{array}{l}\text { Median GPC3 positivity across } \\
\text { all articles, } \%\end{array}$ & IQR \\
\hline Synovial sarcoma & 2 & 76 & 3 & NA \\
\hline \multicolumn{5}{|l|}{ Urogenital cancer } \\
\hline Bladder cancer & 4 & 97 & 15 & $10-29$ \\
\hline Prostate cancer & 3 & 251 & 3 & NA \\
\hline Chromophobe & 4 & 93 & 14 & $2-65$ \\
\hline Clear cell & 4 & 654 & 1 & $0-4$ \\
\hline Oncocytoma & 3 & 40 & 11 & NA \\
\hline Papillary & 4 & 149 & 5 & $1-21$ \\
\hline Wilms tumor & 3 & 87 & 38 & NA \\
\hline Nondysgerminomas & 9 & 153 & 100 & $61-100$ \\
\hline Nonseminomas & 11 & 430 & 52 & $43-100$ \\
\hline Seminomas & 7 & 243 & 0 & $0-8$ \\
\hline \multicolumn{5}{|l|}{ Other } \\
\hline Malignant rhabdoid tumor & 3 & 34 & 12 & NA \\
\hline NET/NEC & 5 & 321 & 0 & $0-2$ \\
\hline Salivary gland tumor & 2 & 71 & 3 & NA \\
\hline
\end{tabular}

${ }^{*}$ One article did not specify the histologic subtype of colorectal patients.

${ }^{\dagger}$ Testicular/ovarian origin not clearly specified.

AFP, $\alpha$-fetoprotein producing; CNS, central nervous system; GPC3, glypican 3; HCC, hepatocellular carcinoma; IQR, interquartile range; NA, not applicable; NEC, neuroendocrine carcinoma; NET, neuroendocrine tumor; NOS, not otherwise specified; SCC, squamous cell cancer; YST, yolk sac tumor.

indicated by IHC data. For 16 of these, the relative difference was less than $10 \%$. The largest discrepancy was seen for leiomyosarcoma. For this tumor, a GPC3 protein overexpression of $35 \%$ was predicted by FGmRNA profiling $(n=60)$, compared with $3 \%$ indicated by IHC analysis in three studies $(n=237)$. For 13 tumor types and subtypes a higher rate of GPC 3 expression in tumors was reported with IHC compared with FGmRNA profiling. For 10 of this group, the relative difference was $\leq 10 \%$. In liposarcoma, GPC 3 protein overexpression was present in $52 \%$ of the 29 cases with IHC analysis in one study compared with $11 \%$ with FGmRNA profiling $(n=76)$. For estrogen receptor-positive breast cancer $(13 \%)$ and neuroblastoma (2\%), FGmRNA profiling and IHC showed the exact same results.

\section{Discussion}

This study shows that FGmRNA profiling can be used as a screening tool to predict GPC3 overexpression across 60 tumor types and subtypes as validated by comparison with IHC staining of a breast cancer TMA and literature data reporting IHC GPC3 overexpression in tumors. In HCC, squamous cell lung cancer and head and neck squamous cell cancer the percentages of samples with predicted GPC3 overexpression were $77 \%, 45 \%$, and $19 \%$, respectively, and these tumor types and subtypes are therefore of interest for GPC3-directed therapies.

In high-incidence tumor types such as colorectal cancer, breast cancer, and prostate cancer, less than $15 \%$ of samples overexpress GPC3. Although GPC3 expression was $<15 \%$ in $78 \%$ of the tumor types and subtypes studied, this can be relevant to the increasing use of personalized treatment strategies. This is exemplified by the $8 \%$ of triple negative breast cancers that had GPC3 overexpression. For this highly aggressive breast cancer subtype, targeted treatment options are lacking. ${ }^{28}$ Recently, the US Food and Drug Administration approved for the first time a cancer treatment based on a tumor biomarker: pembrolizumab for treatment of microsatellite instability-high or mismatchrepair-deficient advanced solid tumors independent of the tumor's original location. This approval might pave the way for registration of additional compounds in the near future to treat tumors with specific features, such as GPC3 overexpression, independent of their origin.

There are some pitfalls concerning FGmRNA profiling, which was used as a screening tool to assess GPC 3 overexpression across a very large set of samples representing many tumor types and subtypes. For example, mRNA might not always be translated to protein or the protein might not end up on the cell membrane and therefore mRNA data 
must be interpreted with some caution. ${ }^{29}$ In addition, FGmRNA profiling does not inform about target heterogeneity and it cannot distinguish between tumor cells and nontumor cells as a source of target overexpression. However, FGmRNA profiling does offer an educated guess to answer questions concerning antigen target overexpression across tumors in a more efficient manner than large-scale IHC analyses, which is used most often in the clinic to assess protein presence. Subsequent IHC validation might be warranted.

To validate predicted GPC3 overexpression at the protein level, the predictions were compared with our own IHC analysis in breast cancer patients or historical IHC data from the literature. In breast cancer, comparable results were shown for GPC3 overexpression in all subgroups, for other tumor types and subtypes corresponding results were found in the majority of tumor types and subtypes. However, there were some limitations to this comparison with historical IHC data in literature. Major heterogeneity in staining antibodies, scoring methods, and cut-off boundaries for GPC3 positivity in the 166 included studies hampered direct comparison. It has been clearly illustrated that a lack of standardized protocols has had a strong impact on IHC results. ${ }^{30}$

In addition to IHC, other techniques such as mass spectrometry or Western blot analysis also can be applied to study protein abundance in tissues. However, all of these techniques require the availability of tumor tissue samples and therefore come with limitations including invasiveness, procedural risks, and accessibility of tumor to biopsy. In addition, only static information is provided and heterogeneity is not taken into account. Alternatively, molecular imaging, defined as the visualization, characterization, and measurement of biological processes at molecular and cellular levels, can be used to study protein expression. ${ }^{31}$ This tool provides whole-body information regarding (heterogeneity in) protein expression in a noninvasive manner and increasingly is being implemented in drug development and patient care. ${ }^{32}$ FGmRNA profiling can be used as a tool to select suitable targets for molecular imaging, as has been shown by Koller et $\mathrm{al}^{33}$ for pancreatic ductal adenocarcinomas.

These data show the percentage of patients per tumor type and subtype who might benefit from GPC3-directed therapies. GPC3-targeting monoclonal antibodies, bispecific T-cell-redirecting antibodies, peptide vaccinations, dendritic cell vaccinations, and chimeric antigen receptors have been engineered and mainly are being explored in early clinical trials involving HCC patients. ${ }^{34-39}$ Potentially interesting results have been seen with peptide vaccinations, provoking partial responses in a subset of patients with advanced HCC or refractory ovarian clear cell carcinoma. ${ }^{34,40}$ Dendritic cell vaccine therapy increased the 5-year recurrence-free survival rate in a few $\mathrm{HCC}$ patients who received dendritic cell vaccine therapy as compared with 31 historical control patients. $^{36}$ The role of GPC3-directed bispecific
T-cell-redirecting antibodies and chimeric antigen receptors currently are being explored in HCC (ClinicalTrials.gov; identifiers NCT02905188, NCT02723942, NCT02715362, NCT02395250, NCT02959151, NCT03130712, NCT03084380, and NCT03146234), squamous cell lung carcinoma (identifier NCT02876978), and (pediatric) solid tumors (NCT02748837 and NCT02932956).

In conclusion, the present study provides a data-driven prioritization of tumor types for future research with GPC3targeting therapies.

\section{Acknowledgment}

We thank the other studies using IHC to determine GPC3 protein overexpression that could not be included because of spatial limitations.

\section{Supplemental Data}

Supplemental material for this article can be found at https://doi.org/10.1016/j.ajpath.2018.05.014.

\section{References}

1. Iglesias BV, Centeno G, Pascuccelli H, Ward F, Peters MG, Filmus J, Puricelli L, de Kier Joffe EB: Expression pattern of glypican-3 (GPC3) during human embryonic and fetal development. Histol Histopathol 2008, 23:1333-1340

2. Morford LA, Davis C, Jin L, Dobierzewska A, Peterson ML, Spear BT: The oncofetal gene glypican 3 is regulated in the postnatal liver by zinc fingers and homeoboxes 2 and in the regenerating liver by alpha-fetoprotein regulator 2. Hepatology 2007, 46:1541-1547

3. Abdul-Al HM, Makhlouf HR, Wang G, Goodman ZD: Glypican-3 expression in benign liver tissue with active hepatitis $\mathrm{C}$ : implications for the diagnosis of hepatocellular carcinoma. Hum Pathol 2008, 39: 2009-2012

4. Llovet JM, Chen Y, Wurmbach E, Roayaie S, Fiel MI, Schwartz M, Thung SN, Khitrov G, Zhang W, Villanueva A, Battiston C, Mazzaferro V, Bruix J, Waxman S, Friedman SL: A molecular signature to discriminate dysplastic nodules from early hepatocellular carcinoma in HCV cirrhosis. Gastroenterology 2006, 131:1758-1767

5. Cai MY, Tong ZT, Zheng F, Liao YJ, Wang Y, Rao HL, Chen YC, Wu QL, Liu YH, Guan XY, Lin MC, Zeng YX, Kung HF, Xie D: EZH2 protein: a promising immunomarker for the detection of hepatocellular carcinomas in liver needle biopsies. Gut 2011, 60:967-976

6. Hirabayashi K, Kurokawa S, Maruno A, Yamada M, Kawaguchi Y, Nakagohri T, Mine T, Sugiyama T, Tajiri T, Nakamura N: Sex differences in immunohistochemical expression and capillary density in pancreatic solid pseudopapillary neoplasm. Ann Diagn Pathol 2015, 19:45-49

7. Honsova E, Lodererova A, Frankova S, Oliverius M, Trunecka P Glypican-3 immunostaining significantly improves histological diagnosis of hepatocellular carcinoma. Cas Lek Cesk 2011, 150: $37-40$

8. Swanson BJ, Yearsley MM, Marsh W, Frankel WL: A triple stain of reticulin, glypican-3, and glutamine synthetase: a useful aid in the diagnosis of liver lesions. Arch Pathol Lab Med 2015, 139:537-542

9. Nguyen T, Phillips D, Jain D, Torbenson M, Wu TT, Yeh MM, Kakar S: Comparison of 5 immunohistochemical markers of hepatocellular differentiation for the diagnosis of hepatocellular carcinoma. Arch Pathol Lab Med 2015, 139:1028-1034 
10. Liu X, Wang SK, Zhang K, Zhang H, Pan Q, Liu Z, Pan H, Xue L, Yen Y, Chu PG: Expression of glypican 3 enriches hepatocellular carcinoma development-related genes and associates with carcinogenesis in cirrhotic livers. Carcinogenesis 2015, 36:232-242

11. Ikeda H, Sato Y, Yoneda N, Harada K, Sasaki M, Kitamura S, Sudo Y, Ooi A, Nakanuma Y: $\alpha$-Fetoprotein-producing gastric carcinoma and combined hepatocellular and cholangiocarcinoma show similar morphology but different histogenesis with respect to SALL4 expression. Hum Pathol 2012, 43:1955-1963

12. Foda AA, Mohammad MA, Abdel-Aziz A, El-Hawary AK: Relation of glypican-3 and E-cadherin expressions to clinicopathological features and prognosis of mucinous and non-mucinous colorectal adenocarcinoma. Tumour Biol 2015, 36:4671-4679

13. Yu X, Li Y, Chen SW, Shi Y, Xu F: Differential expression of glypican-3 (GPC3) in lung squamous cell carcinoma and lung adenocarcinoma and its clinical significance. Genet Mol Res 2015, 14 : $10185-10192$

14. Yamanaka K, Ito $\mathrm{Y}$, Okuyama $\mathrm{N}$, Noda $\mathrm{K}$, Matsumoto $\mathrm{H}$, Yoshida H, Miyauchi A, Capurro M, Filmus J, Miyoshi E: Immunohistochemical study of glypican 3 in thyroid cancer. Oncology 2007, 73:389-394

15. Baumhoer D, Tornillo L, Stadlmann S, Roncalli M, Diamantis EK, Terracciano LM: Glypican 3 expression in human nonneoplastic, preneoplastic, and neoplastic tissues: a tissue microarray analysis of 4,387 tissue samples. Am J Clin Pathol 2008, 129:899-906

16. Cao D, Li J, Guo CC, Allan RW, Humphrey PA: SALL4 is a novel diagnostic marker for testicular germ cell tumors. Am J Surg Pathol 2009, 33:1065-1077

17. Wang F, Liu A, Peng Y, Rakheja D, Wei L, Xue D, Allan RW, Molberg KH, Li J, Cao D: Diagnostic utility of SALL4 in extragonadal yolk sac tumors: an immunohistochemical study of 59 cases with comparison to placental-like alkaline phosphatase, alpha-fetoprotein, and glypican-3. Am J Surg Pathol 2009, 33: $1529-1539$

18. Fehrmann RS, Karjalainen JM, Krajewska M, Westra HJ, Maloney D, Simeonov A, Pers TH, Hirschhorn JN, Jansen RC, Schultes EA, van Haagen HH, de Vries EG, te Meerman GJ, Wijmenga C, van Vugt MA, Franke L: Gene expression analysis identifies global gene dosage sensitivity in cancer. Nat Genet 2015, 47:115-125

19. Barrett $T$, Wilhite SE, Ledoux $P$, Evangelista C, Kim IF, Tomashevsky M, Marshall KA, Philippy KH, Sherman PM, Holko M, Yefanov A, Lee H, Zhang N, Robertson CL, Serova N, Davis S, Soboleva A: NCBI GEO: archive for functional genomics data setsupdate. Nucleic Acids Res 2013, 41:D991-D995

20. Bolstad BM, Irizarry RA, Astrand M, Speed TP: A comparison of normalization methods for high density oligonucleotide array data based on variance and bias. Bioinformatics 2003, 19:185-193

21. Crijns AP, Fehrmann RS, de Jong S, Gerbens F, Meersma GJ, Klip HG, Hollema H, Hofstra RM, te Meerman GJ, de Vries EG, van der Zee AG: Survival-related profile, pathways, and transcription factors in ovarian cancer. PLoS Med 2009, 6:e24

22. Heijink DM, Fehrmann RS, de Vries EG, Koornstra JJ, Oosterhuis D, van der Zee AG, Kleibeuker JH, de Jong S: A bioinformatical and functional approach to identify novel strategies for chemoprevention of colorectal cancer. Oncogene 2011, 30:2026-2036

23. Bense RD, Sotiriou C, Piccart-Gebhart MJ, Haanen JB, van Vugt MA, de Vries EG, Schroder CP, Fehrmann RS: Relevance of tumorinfiltrating immune cell composition and functionality for disease outcome in breast cancer. J Natl Cancer Inst 2016, 109:1-9

24. Lamberts LE, de Groot DJ, Bense RD, de Vries EG, Fehrmann RS: Functional genomic mRNA profiling of a large cancer data base demonstrates mesothelin overexpression in a broad range of tumor types. Oncotarget 2015, 6:28164-28172
25. Moek KL, de Groot DJA, de Vries EGE, Fehrmann RSN: The antibody-drug conjugate target landscape across a broad range of tumour types. Ann Oncol 2017, 28:3083-3091

26. Kononen J, Bubendorf L, Kallioniemi A, Barlund M, Schraml P, Leighton S, Torhorst J, Mihatsch MJ, Sauter G, Kallioniemi OP: Tissue microarrays for high-throughput molecular profiling of tumor specimens. Nat Med 1998, 4:844-847

27. Camp RL, Charette LA, Rimm DL: Validation of tissue microarray technology in breast carcinoma. Lab Invest 2000, 80:1943-1949

28. Denkert C, Liedtke C, Tutt A, von Minckwitz G: Molecular alterations in triple-negative breast cancer - the road to new treatment strategies. Lancet 2017, 389:2430-2442

29. Damelin M, Zhong W, Myers J, Sapra P: Evolving strategies for target selection for antibody-drug conjugates. Pharm Res 2015, 32:3494-3507

30. Gaber R, Watermann I, Kugler C, Reinmuth N, Huber RM, Schnabel PA, Vollmer E, Reck M, Goldmann T: Correlation of EGFR expression, gene copy number and clinicopathological status in NSCLC. Diagn Pathol 2014, 9:165

31. Mankoff DA: A definition of molecular imaging. J Nucl Med 2007, 48: $18 \mathrm{~N}-21 \mathrm{~N}$

32. Moek KL, Giesen D, Kok IC, de Groot DJA, Jalving M, Fehrmann RSN, Lub-de Hooge MN, Brouwers AH, de Vries EGE: Theranostics using antibodies and antibody-related therapeutics. J Nucl Med 2017, 58:83S-90S

33. Koller M, Hartmans E, de Groot DJA, Zhao XJ, van Dam GM, Nagengast WB, Fehrmann RSN: Data-driven prioritization and review of targets for molecular-based theranostic approaches in pancreatic cancer. J Nucl Med 2017, 58:1899-1903

34. Sawada Y, Yoshikawa T, Nobuoka D, Shirakawa H, Kuronuma T, Motomura Y, Mizuno S, Ishii H, Nakachi K, Konishi M, Nakagohri T, Takahashi S, Gotohda N, Takayama T, Yamao K, Uesaka K, Furuse J, Kinoshita T, Nakatsura T: Phase I trial of a glypican-3-derived peptide vaccine for advanced hepatocellular carcinoma: immunologic evidence and potential for improving overall survival. Clin Cancer Res 2012, 18 : 3686-3696

35. Gao H, Li K, Tu H, Pan X, Jiang H, Shi B, Kong J, Wang H, Yang S, Gu J, Li Z: Development of T cells redirected to glypican-3 for the treatment of hepatocellular carcinoma. Clin Cancer Res 2014, 20:6418-6428

36. Lee JH, Lee Y, Lee M, Heo MK, Song JS, Kim KH, Lee H, Yi NJ, Lee KW, Suh KS, Bae YS, Kim YJ: A phase I/IIa study of adjuvant immunotherapy with tumour antigen-pulsed dendritic cells in patients with hepatocellular carcinoma. Br J Cancer 2015, 113:1666-1676

37. Zhu AX, Gold PJ, El-Khoueiry AB, Abrams TA, Morikawa H, Ohishi N, Ohtomo T, Philip PA: First-in-man phase I study of GC33, a novel recombinant humanized antibody against glypican-3, in patients with advanced hepatocellular carcinoma. Clin Cancer Res 2013, 19: 920-928

38. Ikeda M, Ohkawa S, Okusaka T, Mitsunaga S, Kobayashi S, Morizane C, Suzuki I, Yamamoto S, Furuse J: Japanese phase I study of GC33, a humanized antibody against glypican-3 for advanced hepatocellular carcinoma. Cancer Sci 2014, 105:455-462

39. Abou-Alfa GK, Puig O, Daniele B, Kudo M, Merle P, Park JW, Ross P, Peron JM, Ebert O, Chan S, Poon TP, Colombo M, Okusaka T, Ryoo BY, Minguez B, Tanaka T, Ohtomo T, Ukrainskyj S, Boisserie F, Rutman O, Chen YC, Xu C, Shochat E, Jukofsky L, Reis B, Chen G, Di Laurenzio L, Lee R, Yen CJ: Randomized phase II placebo controlled study of codrituzumab in previously treated patients with advanced hepatocellular carcinoma. J Hepatol 2016, 65:289-295

40. Suzuki S, Sakata J, Utsumi F, Sekiya R, Kajiyama H, Shibata K, Kikkawa F, Nakatsura T: Efficacy of glypican-3-derived peptide vaccine therapy on the survival of patients with refractory ovarian clear cell carcinoma. Oncoimmunology 2016, 5:e1238542 